\title{
Distribuição geográfica da produção e colaboração científica brasileira nas Ciências Biomédicas
}

\author{
Natascha Helena Franz Hoppen \\ Mestre; Universidade Federal do Rio Grande do Sul, Porto Alegre, RS, Brasil; \\ na.hoppen@hotmail.com \\ Dirce Maria Santin \\ Doutoranda; Universidade Federal do Rio Grande do Sul, Porto Alegre, RS, Brasil; \\ dirce.santin@ufrgs.br \\ Maurício de Vargas Corrêa \\ Mestrando; Universidade Federal do Rio Grande do Sul, Porto Alegre, RS, Brasil \\ mauricio.be@hotmail.com \\ Samile Andréa de Souza Vanz \\ Doutora; Universidade Federal do Rio Grande do Sul, Porto Alegre, RS, Brasil; \\ samilevanz@terra.com.br
}

Resumo: As Ciências Biomédicas constituem um importante campo de pesquisa no Brasil, tanto pelo estudo de doenças locais típicas quanto pelo enfoque em temas de interesse universal. Este estudo faz inicialmente um levantamento da institucionalização das Ciências Biomédicas no Brasil e, depois, analisa a distribuição geográfica da produção e da colaboração científica dessas áreas no país, a fim de compreender as configurações atuais do campo e a concentração e dispersão das pesquisas no território nacional. Trata-se de uma pesquisa bibliométrica realizada com base nos artigos publicados na última década (20062015) por pesquisadores brasileiros em periódicos indexados na Web of Science. Os resultados revelam a concentração da produção em poucos estados, com destaque para São Paulo, presente em quase 50\% dos artigos e sendo o mais colaborativo com unidades federativas de outras regiões do país. Outro destaque é o estado do Rio de Janeiro, segundo mais produtivo e responsável, junto com São Paulo, pelos cinco periódicos que mais publicaram artigos da área no período estudado. Minas Gerais, Rio Grande do Sul, Paraná e Santa Catarina são os estados seguintes em termos de produtividade. Os clusters de colaboração são formados por estados da mesma região ou próximos geograficamente. Pernambuco e Espírito Santo são também unidades federativas com destaque para seus modos de produção e papel de colaboração em seus clusters. Os estados do norte do país são os menos produtivos, seguidos pelos da região Nordeste, o que aponta necessidade de mais políticas públicas para o desenvolvimento científico dessas regiões. Conclui-se que a proximidade geográfica é um fator importante na colaboração e mesmo na produtividade, tendo em vista que estados mais produtivos estão próximos entre si e se mostram bastante colaborativos.

Palavras-chave: Bibliometria. Cientometria. Ciências Biomédicas. Brasil. Produção científica. Colaboração científica. Análise geográfica. 


\section{Introdução}

As últimas décadas foram marcadas pela rápida ampliação da produção científica brasileira. Entre os anos 2006 a 2008, o Brasil cresceu cerca de 12\% em número de publicações e cerca de $3 \%$ em investimentos em ciência. Em anos mais recentes, o país manteve o aumento da produtividade, com média aproximada de $8 \%$ de crescimento anual, e o incremento de investimentos públicos para a pesquisa e a qualificação de recursos humanos para a ciência, os quais passaram a atingir certa estabilidade nos últimos anos (LETA; THIJS; GLÄNZEL, 2013; ROYAL SOCIETY, 2011).

Apesar do crescimento acelerado, os estudos sobre a produção científica brasileira apontam disparidades entre diferentes estados e regiões do país no que diz respeito a aspectos como produtividade, perfil de colaboração e impacto (GLÄNZEL; LETA; THIJS, 2006; SIDONE; HADDAD; MENA-CHALCO, 2016; VANZ; STUMPF, 2012). Embora a diferença de produtividade seja uma situação considerada comum quando regiões próximas são comparadas, considera-se que a disparidade entre os estados brasileiros é muito elevada e pode vir a ser um obstáculo no desenvolvimento das regiões (GLÄNZEL; LETA; THIJS, 2006). A heterogeneidade também pode ser visualizada quando se analisa a colaboração científica, evidenciando a necessidade de descentralização das atividades de pesquisa no Brasil, processo que pode estimular o desenvolvimento de regiões menos favorecidas e permitir a resolução de problemas locais (SIDONE; HADDAD; MENA-CHALCO, 2016).

A ciência e a tecnologia estão se tornando cada vez mais internacionais, mas os requisitos para participar de seus benefícios continuam sendo de ordem local e nacional e dependem de ações deliberadas por parte dos governos (SCHWARTZMAN, 2015). A análise das publicações dos grupos de pesquisa brasileiros em 2010 identificou que 73\% das publicações são originárias de São Paulo, Rio de Janeiro, Rio Grande do Sul e Minas Gerais, sendo o estado de São Paulo, sozinho, responsável por 33\% desse total (SCHWARTZMAN, 2015). A análise das publicações indexadas em bases de dados internacionais também indica significativa disparidade: São Paulo é apontado como responsável por mais 
de $20 \%$ da produção científica brasileira, sendo que a cidade de São Paulo figurou em $21^{\circ}$ lugar na lista das cidades mais produtivas do mundo no período 20042008 (ROYAL SOCIETY, 2011).

É importante lembrar que a constituição do estado de São Paulo garante o investimento de $1 \%$ do produto interno bruto (PIB) estadual em pesquisa, o que o torna incomparável, em termos de financiamento de pesquisa, a outros estados brasileiros (FUNDAÇÃO DE AMPARO À PESQUISA DO ESTADO DE SÃO PAULO, 2011). O estado ainda conta com outra vantagem histórica, já que a pósgraduação brasileira teve início na região Sudeste (CASTRO, 1986). Algumas áreas, como Física e Ciências Biológicas, estavam estabelecidas no estado e ofereciam programas de mestrado e doutorado em 1965, três anos antes da promulgação da Lei no 5.540, de 1968 (BRASIL, 1968), que promoveu a Reforma Universitária no país, institucionalizou a pós-graduação e favoreceu as condições para a realização das atividades de pesquisa nas universidades.

A tardia institucionalização do ensino superior no Brasil, assim como as dificuldades econômicas e a desigualdade entre os estados e as regiões, levou a um crescimento lento e desorganizado da ciência nacional. Meis e Leta (1996) sugerem que o processo de institucionalização da pesquisa científico-tecnológica brasileira se iniciou no século XX, portanto dois séculos após a Europa e os Estados Unidos, um atraso provocado especialmente por aspectos históricos referentes à colonização do país. Na segunda metade do século XX, a Reforma Universitária e o surgimento da pós-graduação no Brasil elevaram a ciência nacional a um novo patamar, o que resultou no fortalecimento das universidades e formou as bases para o desenvolvimento da ciência e para o crescimento da produção científica registrado no início do século XXI.

A heterogeneidade na distribuição geográfica da ciência brasileira se sustenta, igualmente, em aspectos históricos ligados ao desenvolvimento do país e de suas regiões. Apesar dos esforços empreendidos pelo governo nos últimos anos no sentido de incentivar o desenvolvimento científico das diversas regiões, ainda persiste uma clara desigualdade entre os estados e as regiões brasileiras nas 
diversas áreas do conhecimento, mesmo que esta se mostre mais ou menos acentuada em alguns campos.

De acordo com Schwartzman (2015), as Ciências Biológicas constituem a base da própria ciência brasileira, visto que tiveram origem nos estudos descritivos da fauna e da flora realizados por pesquisadores e viajantes estrangeiros nos tempos do Império. A publicação da Teoria da Evolução de Charles Darwin provocou novos estudos sobre a evolução biológica e promoveu o avanço da ciência no mundo todo. No Brasil, a área apresentou maior desenvolvimento no século XX, com a instalação de importantes institutos de pesquisa e a consolidação do ensino e da pesquisa nas universidades. Atualmente, as Ciências Biológicas constituem uma das áreas mais consolidadas do país, com forte impacto social, cultural e econômico, além de relevância nacional e internacional (SANTIN; VANZ; STUMPF, 2015).

As áreas biomédicas reúnem enfoques específicos das Ciências Biológicas e da Saúde. Suas pesquisas têm grande importância em contextos locais, devido a particularidades que influem diretamente nas condições de saúde e na evolução das doenças de cada região, tais como condições climáticas, saneamento básico, desenvolvimento econômico e até mesmo aspectos culturais. Por outro lado, boa parte das áreas abrangidas pelas Ciências Biomédicas se caracteriza pelo enfoque na pesquisa básica, dedicando-se a temas de interesse global, aspecto que lhes confere alcance internacional.

A Organização Mundial de Saúde, por exemplo, indica a necessidade de desenvolvimento de pesquisas em saúde mental em todas as regiões do mundo, devido ao aumento de doenças neurológicas e mentais advindas do envelhecimento geral da população mundial e dos aspectos sociais da vida contemporânea, que têm contribuído para o aumento de doenças como depressão e ansiedade (WORLD HEALTH ORGANIZATION, 2001). Os dados de publicação e colaboração científica dos estados brasileiros no contexto atual podem oportunizar o conhecimento da estrutura científica e da distribuição geográfica das pesquisas do campo, fornecendo subsídios para as políticas voltadas ao desenvolvimento da área no Brasil. Por outro lado, a compreensão das 
configurações atuais das Ciências Biomédicas no Brasil e de sua distribuição geográfica exige o conhecimento dos principais aspectos históricos que contribuíram para a formação das instituições e para o estabelecimento de uma estrutura de pesquisa para essas áreas no país.

A partir das ideias expostas, este trabalho propõe a análise da distribuição da atividade e da colaboração nas Ciências Biomédicas entre as unidades federativas brasileiras por meio do mapeamento da produtividade, participação e coautoria nas publicações científica dos dez últimos anos (2006-2015), a fim de se compreender o desenvolvimento dessas áreas, cuja importância é estratégica para o Brasil no contexto nacional e internacional. A próxima seção do artigo apresenta o histórico das Ciências Biomédicas no Brasil, enquanto a terceira seção apresenta a metodologia do estudo, seguida pelos resultados e conclusões.

\section{Institucionalização das Ciências Biomédicas no Brasil}

A criação dos primeiros institutos de pesquisa em saúde na Europa, no final do século XIX, foi impulsionada por uma série de descobertas científicas sobre os micro-organismos causadores de doenças infecciosas. Os primeiros institutos foram criados para o controle dessas doenças, a exemplo do Institut Pasteur, inaugurado em 1888, em Paris, do British Institute of Preventive Medicine (mais tarde chamado Lister Institute), inaugurado em 1891, em Londres, e do Institute für Infektionskrankheiten (mais tarde Institute Robert Koch), de Berlim (CAMARGO; SANT’ANNA, 2004).

De acordo com Schwartzman (2015) a atividade científica realizada de forma sistemática e com apoio institucional (ou seja, praticada fora de laboratórios leigos de cientistas solitários, características dos primórdios científicos) teve início tardio no Brasil, especialmente em comparação com outros países que também tiveram histórico de colonização. França, Inglaterra e Holanda, por exemplo, transmitiram a herança científica para suas colônias, diferentemente de Portugal. O breve período de colonização holandesa no nordeste do país, entre 1630 e 1654, trouxe estudiosos de Geografia, Zoologia e 
Botânica, cujos trabalhos não tiveram continuidade após a retomada da região por Portugal. A Revolução Científica do século XV e o início da ciência moderna dos séculos XVI e XVII, por exemplo, não tiveram repercussões aqui (MOTOYAMA, 2004). Foi apenas com a vinda da família real portuguesa para o Brasil, em 1808, que a atividade científica organizada e sua institucionalização tiveram início em território brasileiro (MEIS; LETA, 1996).

Com a transferência da corte portuguesa, áreas como Medicina e Cirurgia se tornaram prioritárias, por razões militares e também para a proteção da saúde pública. Nesse contexto, a Bahia, que era um dos maiores e mais importantes centros urbanos, recebeu a primeira escola de Medicina do país (SCHWARTZMAN, 2015). A Escola de Cirurgia da Bahia foi fundada em 1808, seguida, no mesmo ano, pela criação da Escola Anatômica, Cirúrgica e Médica do Rio de Janeiro, com a finalidade de formar cirurgiões aptos a tratar os doentes a bordo dos navios, além da população residente no país. Os currículos, predominantemente práticos, formavam cirurgiões que fundaram, em 1829, a Sociedade de Medicina do Rio de Janeiro, mais tarde denominada Academia Nacional de Medicina (em 1889), demonstrando a profissionalização e o prestígio da área no Brasil.

A pesquisa brasileira em saúde também nasceu entre médicos e professores da Escola de Medicina da Bahia (CAMARGO; SANT'ANNA, 2004). Embora o ensino e a formação profissional tenham sido a prioridade da instituição durante a primeira metade do século XIX, mais tarde foi determinado que de três em três anos seria escolhido um professor, nomeado pelo governo, para realizar pesquisas e investigações científicas no Brasil ou no exterior (ESCOLA..., 2015). A iniciativa demonstra a preocupação com o desenvolvimento da Medicina no país e o papel que a Escola de Medicina da Bahia e sua congênere no Rio de Janeiro poderiam desempenhar nesse sentido.

Por volta de 1850 surgiu um movimento denominado Escola Tropicalista Baiana, que deu contribuições importantes para a identificação da epidemia de febre amarela em 1849 e da cólera em 1853. Em 1866 iniciou-se a publicação da Gazeta Médica da Bahia, que foi o veículo de divulgação dos trabalhos do grupo 
até 1908 (SCHWARTZMAN, 2015). Os tropicalistas faziam parte de uma rede informal de médicos, geograficamente isolados nos domínios coloniais europeus, que estavam interessados no papel desempenhado pelos parasitos na produção de doenças. O grupo se correspondia, trocava espécimes e se mantinha atualizado em relação aos estudos desenvolvidos pelos colegas estrangeiros através de periódicos, livros e encontros ocasionais durante viagens à Europa (EDLER, 1999 ${ }^{1}$ apud BENCHIMOL, 2004). Desse modo, já era possível observar a participação dos pesquisadores brasileiros em redes de colaboração científica nas áreas biomédicas e seu interesse no intercâmbio de informações e na colaboração com pesquisadores europeus.

Durante o Segundo Império e a primeira década da República, a Medicina brasileira era principalmente clínica e sanitária, e os médicos eram consultados sobre a organização urbana, a construção de esgotos e temas do gênero. A moderna Medicina e a pesquisa bacteriológica e sanitária começaram em São Paulo, em parte devido ao ímpeto dado às iniciativas educacionais, científicas e tecnológicas naquele estado nos primeiros anos do regime republicano. Outro fator importante foram as condições precárias da cidade de Santos, que passava a ser o porto mais movimentado do Brasil. Em 1899, com a disseminação da peste bubônica no porto de Santos, autoridades sugeriram a criação de um laboratório com o objetivo de produzir soros preventivos e curativos. A iniciativa buscava conquistar a autonomia do país em relação a outras nações, de onde a maioria dos medicamentos era proveniente. O laboratório esteve inicialmente anexado ao Instituto Bacteriológico do Estado de São Paulo e mais tarde, em 1901, foi desvinculado da instituição, passando a se chamar Instituto Serumterápico do Estado de São Paulo e, posteriormente, Instituto Butantan (CAMARGO; SANT'ANNA, 2004; SCHWARTZMAN, 2015; LABORATÓRIO..., 2015).

Outros importantes institutos de pesquisas nas áreas biológicas e da saúde foram criados na época. O Instituto Pasteur do Rio de Janeiro, pioneiro no país, foi criado em 1888 vinculado à Santa Casa do Rio de Janeiro, com o objetivo de produzir vacinas contra a raiva (CAMARGO; SANT'ANNA, 2004). O Instituto Adolfo Lutz, fundado em 1893 pelo governo paulista, se dedicava à 
pesquisa microbiológica e bacteriológica e à fabricação de vacinas, além da promoção de campanhas contra a febre amarela e a peste bubônica. Já o Instituto Oswaldo Cruz foi criado em 1900 na cidade do Rio de Janeiro para atender à necessidade de preparo de soros e vacinas antipestosas para o enfrentamento da peste bubônica. O Instituto lançou, em 1909, a revista Memórias do Instituto Oswaldo Cruz, reconhecida como um dos principais periódicos brasileiros das áreas biomédicas. O Instituto Biológico, por sua vez, foi criado pelo governo paulista em 1927 com a finalidade de promover pesquisa básica e aplicada, desenvolver medidas de proteção dos produtos agrícolas, ensinar sua utilização adequada e produzir soros e vacinas contra doenças animais. O Instituto publicou dois importantes periódicos que se mantêm correntes na atualidade: Arquivos do Instituto Biológico e O Biológico (VALLE, 1979; SCHWARTZMAN, 2015).

Os institutos foram responsáveis por muito do que foi produzido pela ciência brasileira na primeira metade do século XX. Segundo Valle (1979), descobertas nos domínios científicos da Parasitologia, Microbiologia, Micologia e Patologia Experimental, e diversos outros de não menor importância, constituem a maior e melhor contribuição brasileira para a Medicina universal. Atualmente, os institutos de pesquisa desempenham um papel importante no avanço do conhecimento científico e no desenvolvimento de soluções para os problemas de saúde que atingem a população. Conhecer sua história é essencial para a compreensão da estrutura das Ciências Biomédicas no Brasil, bem como os possíveis reflexos dessa institucionalização na produção e colaboração científica da área.

Os institutos de pesquisa foram criados com o objetivo de atender às necessidades explícitas de saúde no Brasil. No entanto, alguns também estavam voltados à pesquisa básica, como o Instituto Bacteriológico de São Paulo e o Instituto Soroterápico Federal, no Rio de Janeiro. O primeiro foi criado com a missão de desenvolver pesquisas em bacteriologia, visando o estudo de epidemias e epizootipias, bem como a produção de vacinas. Já o Instituto Soroterápico (atual Fundação Oswaldo Cruz), foi motivo de disputa entre os seus primeiros diretores. O Barão de Pedro Affonso defendia a produção de 
soros e vacinas, enquanto Oswaldo Cruz era favorável à pesquisa microbiana e à busca de novos patógenos e de novas estratégias de combate, além de privilegiar o ensino e o treinamento de pessoal. Quando Oswaldo Cruz assumiu sua direção, em 1907, o Instituto Soroterápico passou a se chamar Instituto de Patologia Experimental (CAMARGO; SANT'ANNA, 2004), o que de certo modo refletiu a orientação adotada pela instituição. Mais tarde passou a se chamar Instituto Oswaldo Cruz, em homenagem a um de seus principais expoentes.

O breve histórico revela que, embora as pesquisas em saúde tenham se iniciado na Escola de Medicina da Bahia, os primeiros institutos de pesquisa surgiram no final do século XIX e início do século XX na região Sudeste. Com o passar do tempo novas instituições foram sendo criadas em todo o território nacional, e as universidades assumiram um papel importante no desenvolvimento de pesquisas da área. Atualmente as Ciências Biomédicas têm tradição e reconhecimento no Brasil, tanto pela busca de soluções para problemas locais e nacionais, como pela pesquisa em temas de interesse universal. A área está presente em diversas universidades e institutos de pesquisa e contribui para a produtividade e a visibilidade da ciência brasileira no meio científico nacional e internacional. Áreas como Medicina Clínica, Biologia, Bioquímica e Neurociências se destacam tanto por sua produtividade quanto pelo crescimento expressivo de sua produção científica nos últimos anos (FUNDAÇÃO DE AMPARO À PESQUISA DO ESTADO DE SÃO PAULO, 2011; HOPPEN; VANZ, 2016; LETA; THIJS; GLÄNZEL, 2013).

\section{Metodologia}

A pesquisa se constitui num estudo bibliométrico de nível macro, sendo voltada à análise da produção científica brasileira. O corpus da pesquisa é formado por artigos das Ciências Biomédicas com pelo menos um autor vinculado a instituições brasileiras, publicados entre 2006 e 2015 e indexados nas coleções Science Citation Index Expanded, Social Science Citation Index e Arts \& Humanities Citation Index da Web of Science (WoS). O recorte temático é 
composto por 20 categorias de assunto da WoS integrantes da disciplina Ciências da Vida e Biomedicina. A seleção foi feita com base na classificação das áreas biomédicas realizada por Glänzel e Schubert (2003) e ampliada pela compreensão do caráter básico das pesquisas em saúde nas áreas médicas e biológicas no Brasil, tendo por base a experiência dos autores em estudos bibliométricos e em atividades profissionais. Desta forma, as categorias de assunto utilizadas na pesquisa foram: Anatomy \& Morphology, Behavioral Sciences, Biochemical Research Methods, Biochemistry \& Molecular Biology, Biotechnology \& Applied Microbiology, Cell \& Tissue Engineering, Cell Biology, Developmental Biology, Immunology, Medical Laboratory Technology, Microbiology, Mycology, Neurosciences, Parasitology, Pathology, Physiology, Psychology, Biological, Toxicology e Virology.

A coleta de dados ocorreu em $1^{\circ}$ de março de 2016 e a estratégia de busca incluiu a expressão "Brazil OR Brasil" no campo País (CU), com vistas a identificar as pesquisas com pelo menos um autor vinculado a instituições brasileiras. $\mathrm{O}$ download dos dados foi feito com o software Downloader em blocos de 500 registros, posteriormente reunidos com o BibExcel.

A fim de verificar a unidade federativa (UF) de cada artigo com o menor grau de erro possível, foi realizada limpeza manual desses dados. Primeiramente foi feita listagem do campo city country (parte do campo C1) no Bibexcel e posteriormente foi feita a padronização dos registros com a sigla dos estados brasileiros e do Distrito Federal. O Bibexcel identifica como city country a expressão imediatamente anterior ao país, separada deste por vírgula (por exemplo, Sao Paulo, SP, Brazil, onde SP seria considerado o city country). Dessa forma, para limpar essas entradas fez-se necessário adicionar informações padronizadas nessa seção, por exemplo: "Sao Paulo State, Brazil” padronizado ficou como "Sao Paulo State, SP, Brazil", "Diadema, Brazil" foi modificado para "Diadema, SP, Brazil", "BR-05508900 Sao Paulo, Brazil" foi modificado para "BR-05508900 Sao Paulo, SP, Brazil”. Foram corrigidos também erros de registro, como "Teresina, PL, Brazil", "Floriano, PL, Brazil" (ao invés de PI) e "Sao Paolo, Brazil", além de informações dúbias como "CEP, Brazil” (em registros corrigidos para TO, GO, RJ e SP, Brazil). Cada estado foi contado uma 
única vez em cada artigo a fim de se verificar sua participação absoluta na produção científica brasileira, tanto nas análises de colaboração como na distribuição geográfica entre os estados. Todavia, apresenta-se também mapa com análise que leva em conta o número de pesquisadores de cada estado para cada artigo a fim de demonstrar também o peso relativo das unidades federativas.

As análises foram feitas com auxílio dos softwares BibExcel (agrupamento de dados, conferência do número de registros no download e frequências simples), WordPad (limpeza de dados), Microsoft Excel (auxílio na limpeza de dados, tabelas numéricas e estatísticas), Philcarto (mapas de distribuição geográfica da produção científica) e VOSViewer (mapa de colaboração).

\section{Resultados}

Um total de 53.666 artigos com autoria vinculada ao Brasil foram publicados na última década em periódicos das Ciências Biomédicas indexados na WoS (Figura 1). O número de artigos publicados cresceu em linha linear, com coeficiente de determinação $\left(\mathrm{R}^{2}\right)$ de 0,9785 . Entre o primeiro e o último ano da pesquisa houve um crescimento de $73,23 \%$, sendo $6,38 \%$ a média de crescimento anual, com destaque para o crescimento de 2007 para 2008, que foi de $13,74 \%$. Esse conjunto representa $16,59 \%$ do total de artigos brasileiros publicados no mesmo período.

O crescimento das Ciências Biomédicas se compara ao crescimento da ciência brasileira (de todas as áreas), que alcançou cerca de 12\% no período 2006 a 2008, conforme relatório da Royal Society (2011); e 10,7\% de 1980 a 2010, segundo dados de Almeida e Guimarães (2013). Esse percentual de crescimento supera o ritmo anterior ao ingresso de um grande número de periódicos brasileiros na Web of Science, período em que se observava cerca de $8 \%$ ao ano entre 1990 e 2005 (GLÄNZEL; LETA; THIJS, 2006).

O crescimento da ciência brasileira se deve ao aumento na cobertura de periódicos brasileiros na base, mas também ao real aumento da produtividade dos pesquisadores (LETA, 2011), ocasionada em função dos programas de 
incentivo à ciência, realizados especialmente nas duas últimas décadas, e à reforma na avaliação do ensino superior, que passou a avaliar anualmente os programas de pós-graduação e a produção científica de seus membros, principais agentes da ciência no Brasil. Tais incentivos políticos aumentaram a parcela da contribuição brasileira na ciência mundial, estabelecendo o país como potência científica na América Latina (LETA; GLÄNZEL; THIJS, 2006; LETA, 2011; LETA; THIJS; GLÄNZEL, 2013). Por outro lado, a diminuição da média de crescimento ao longo dos anos parece demonstrar estabilização do desenvolvimento científico nacional e de seus incentivos, que tendem a diminuir conforme recentes anúncios de contingenciamento de recursos divulgados pelo governo federal (ROSSI, 2016).

Figura 1 - Crescimento da produção científica brasileira em Ciências Biomédicas, WoS 20062015.

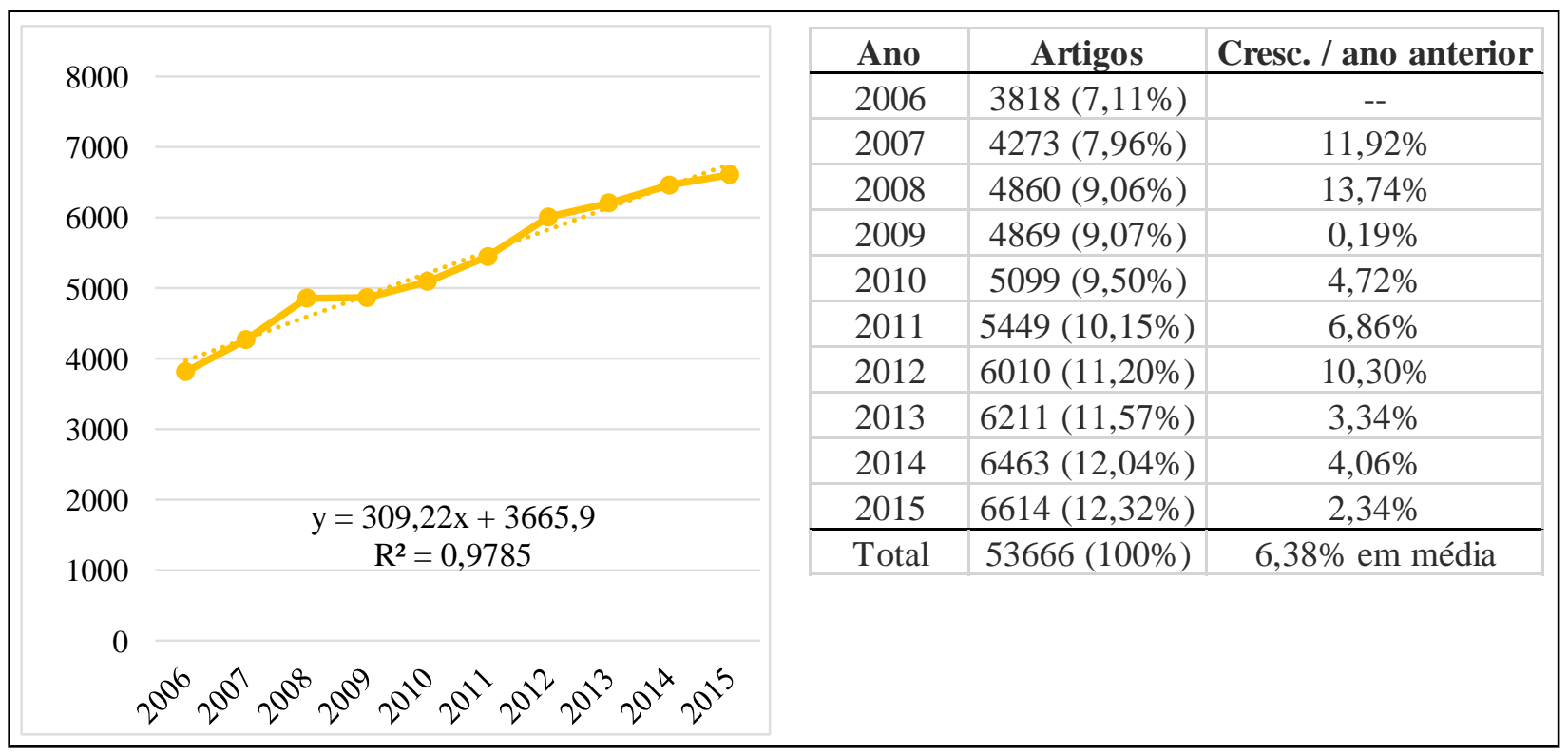

Fonte: Dados da pesquisa.

A amplitude e o enfoque internacional da produção científica das áreas biomédicas se refletem no idioma das publicações, com 98,46\% dos artigos em inglês, e também na dispersão dos artigos em 1.370 periódicos distintos, com destaque para o Arquivos de Neuro-psiquiatria, que publicou 1.579 artigos no período (2,94\%). Os outros idiomas, em ordem de predominância, foram: português, com $732 \operatorname{artigos}(1,36 \%)$, espanhol, com 87 artigos (0,16\%), francês, quatro artigos $(0,01 \%)$, e galês, com um único artigo. 
Por outro lado, os periódicos brasileiros também marcam forte presença na área, ocupando oito posições entre os principais periódicos publicadores e as cinco primeiras posições entre as publicações. Na Tabela 1 são indicados os periódicos com pelo menos 300 artigos brasileiros de Ciências Biomédicas publicados entre 2006 e 2015. A alta dispersão fica visível pelo fato de que a partir do décimo título já se representa um número menor que $1 \%$ do total de artigos. Outro fato interessante, que reforça a presença dos periódicos nacionais, é que dentre os títulos brasileiros, a maior parte é publicada nos estados de São Paulo e Rio de Janeiro.

Tabela 1 - Periódicos com mais de 300 artigos brasileiros de Ciências Biomédicas publicados entre 2006 e 2015 indexados na $W o S$

\begin{tabular}{|c|c|c|c|c|c|c|}
\hline & Periódicos & Artigos & $\%$ & FI 2015 & $\begin{array}{c}\text { País de } \\
\text { publicação }\end{array}$ & $\begin{array}{c}\text { Cidade e UF } \\
\text { (se brasileiro) }\end{array}$ \\
\hline 1 & Arquivos de Neuro-Psiquiatria & 1.579 & $2,94 \%$ & 0.937 & $\mathrm{BR}$ & São Paulo, SP \\
\hline 2 & Genetics and Molecular Research & 1.387 & $2,58 \%$ & 0.764 & BR & Ribeirão Preto, SP \\
\hline 3 & Memórias do Instituto Oswaldo Cruz & 1.264 & $2,36 \%$ & 1.789 & BR & Rio de Janeiro, RJ \\
\hline 4 & Brazilian Journal of Microbiology & 962 & $1,79 \%$ & 0.865 & BR & São Paulo, SP \\
\hline 5 & Genetics and Molecular Biology & 742 & $1,38 \%$ & 1.341 & BR & Ribeirão Preto, SP \\
\hline 6 & Veterinary Parasitology & 613 & $1,14 \%$ & 2.242 & HOL & -- \\
\hline 7 & Revista Brasileira de Medicina do Esporte & 612 & $1,14 \%$ & 0.173 & BR & São Paulo, SP \\
\hline 8 & Revista Brasileira de Parasitologia Veterinária & 610 & $1,14 \%$ & 0.990 & BR & São Paulo, SP \\
\hline 9 & Toxicon & 541 & $1,01 \%$ & 2.309 & ING & -- \\
\hline 10 & Transplantation Proceedings & 525 & $0,98 \%$ & 0.867 & EUA & -- \\
\hline 11 & Parasitology Research & 499 & $0,93 \%$ & 2.027 & EUA & -- \\
\hline 12 & Plos Neglected Tropical Diseases & 481 & $0,90 \%$ & 3.948 & EUA & -- \\
\hline 13 & Crop Breeding and Applied Biotechnology & 448 & $0,83 \%$ & 0.946 & BR & Viçosa, MG \\
\hline 14 & Experimental Parasitology & 445 & $0,83 \%$ & 1.623 & EUA & -- \\
\hline 15 & Biomed Research International & 375 & $0,70 \%$ & 2.134 & EUA & -- \\
\hline 16 & Acta Tropica & 363 & $0,68 \%$ & 2.380 & $\mathrm{HOL}$ & -- \\
\hline 17 & Applied Biochemistry and Biotechnology & 353 & $0,66 \%$ & 1.606 & EUA & -- \\
\hline 18 & Bioresource Technology & 349 & $0,65 \%$ & 4.917 & $\mathrm{HOL}$ & -- \\
\hline 19 & International Journal of Morphology & 348 & $0,65 \%$ & 0.299 & $\mathrm{CHI}$ & -- \\
\hline 20 & Neuroscience Letters & 348 & $0,65 \%$ & 2.107 & HOL & -- \\
\hline 21 & Behavioural Brain Research & 339 & $0,63 \%$ & 3.002 & $\mathrm{HOL}$ & -- \\
\hline 22 & Brain Research & 338 & $0,63 \%$ & 2.561 & $\mathrm{HOL}$ & -- \\
\hline-- & Outros & $<300$ & $<0,60 \%$ & -- & -- & -- \\
\hline
\end{tabular}

Fonte: Dados da pesquisa e Journal Citation Reports (c2015).

Legenda: FI - Fator de Impacto.

A distribuição geográfica mostra que a pesquisa em Ciências Biomédicas está concentrada principalmente no estado de São Paulo, que contribui em quase 
cinco de cada dez artigos publicados $(47,71 \%)$ (Tabela 2). A pesquisa biomédica se concentra nos estados do sudeste e sul do país, sendo o Rio de Janeiro o segundo estado com maior participação nas pesquisas da área (9.157 artigos, 17,06\%), seguido de Minas Gerais (participação em 13,95\% da produção de pesquisa), Rio Grande do Sul (12,50\%), Paraná (7,52\%) e Santa Catarina $(4,78 \%)$.

Os resultados fazem jus ao histórico das Ciências Biomédicas no país, tendo em vista o protagonismo exercido por São Paulo na criação de laboratórios e institutos de pesquisa e na pós-graduação. A Bahia, no entanto, que sediou a primeira escola de medicina do Brasil, não figura entre os polos da pesquisa em Ciências Biomédicas na atualidade. Os mapas apresentados a seguir possibilitam a visualização de como se concentra a pesquisa brasileira na área.

Destaca-se que os estados que concentram a produção brasileira em Ciências Biomédicas se encontram geograficamente próximos, nas regiões Sudeste e Sul. Outro fato que chama a atenção é que os três primeiros estados são responsáveis por alguns dos 22 periódicos mais produtivos do período. Por outro lado, o estado de Pernambuco, situado em sexto lugar em termos de produtividade e participação na pesquisa (2.049 artigos, 3,82\%), se localiza na região Nordeste do país. Sidone, Haddad e Mena-Chalco (2017) afirmam que a capital desse estado (Recife) e Brasília (localizada no Distrito Federal) são as únicas cidades fora da região sul-sudeste que se encontram entre as 50 mais produtivas em ciências no Brasil.

Tabela 2 - Distribuição geográfica da produção científica em Ciências Biomédicas entre as unidades federativas brasileiras, 2006-2015.

\begin{tabular}{|c|c|c|}
\hline Unidade Federativa & Artigos & $\begin{array}{c}\text { Participação na } \\
\text { pesquisa }\end{array}$ \\
\hline 1. São Paulo (SP) & 25.604 & $47,71 \%$ \\
\hline 2. Rio de Janeiro (RJ) & 9.157 & $17,06 \%$ \\
\hline 3. Minas Gerais (MG) & 7.488 & $13,95 \%$ \\
\hline 4. Rio Grande do Sul (RS) & 6.710 & $12,50 \%$ \\
\hline 5. Paraná (PR) & 4.036 & $7,52 \%$ \\
\hline 6. Santa Catarina (SC) & 2.566 & $4,78 \%$ \\
\hline 7. Pernambuco (PE) & 2.049 & $3,82 \%$ \\
\hline 8. Distrito Federal (DF) & 1.998 & $3,72 \%$ \\
\hline
\end{tabular}




\begin{tabular}{|c|c|c|}
\hline Unidade Federativa & Artigos & $\begin{array}{c}\text { Participação na } \\
\text { pesquisa }\end{array}$ \\
\hline 9. Bahia (BA) & 1.763 & $3,29 \%$ \\
\hline 10. Ceará (CE) & 1.389 & $2,59 \%$ \\
\hline 11. Goiás (GO) & 1.110 & $2,07 \%$ \\
\hline 12. Pará (PA) & 1.045 & $1,95 \%$ \\
\hline 13. Rio Grande do Norte (RN) & 857 & $1,60 \%$ \\
\hline 14. Amazonas (AM) & 675 & $1,26 \%$ \\
\hline 15. Mato Grosso do Sul (MS) & 661 & $1,23 \%$ \\
\hline 16. Paraíba (PB) & 597 & $1,11 \%$ \\
\hline 17. Espírito Santo (ES) & 561 & $1,05 \%$ \\
\hline 18. Sergipe $(\mathrm{SE})$ & 438 & $0,82 \%$ \\
\hline 19. Mato Grosso (MT) & 381 & $0,71 \%$ \\
\hline 20. Piauí (PI) & 375 & $0,70 \%$ \\
\hline 21. Alagoas (AL) & 251 & $0,47 \%$ \\
\hline 22. Rondônia (RO) & 195 & $0,36 \%$ \\
\hline 23. Maranhão (MA) & 192 & $0,36 \%$ \\
\hline 24. Tocantins (TO) & 137 & $0,26 \%$ \\
\hline 25. Amapá (AP) & 62 & $0,12 \%$ \\
\hline 26. Acre (AC) & 55 & $0,10 \%$ \\
\hline 27. Roraima (RR) & 28 & $0,05 \%$ \\
\hline
\end{tabular}

Fonte: Dados da pesquisa.

Os demais estados da região Nordeste perfilam menor participação na pesquisa, e os estados do norte são os que registram menor produtividade, como fica evidenciado no mapa da Figura 2. O Espírito Santo é o estado da região Sudeste mais diverso da área em termos de atividade científica, pois tem perfil de atividade similar a estados do nordeste e proximidade com eles, característica distinta dos demais estados do sudeste, mais próximos à região Sul. 
Figura 2 - Distribuição da produção científica em Ciências Biomédicas no território brasileiro entre 2006 e 2015, 1 ponto $=256,04$ artigos.

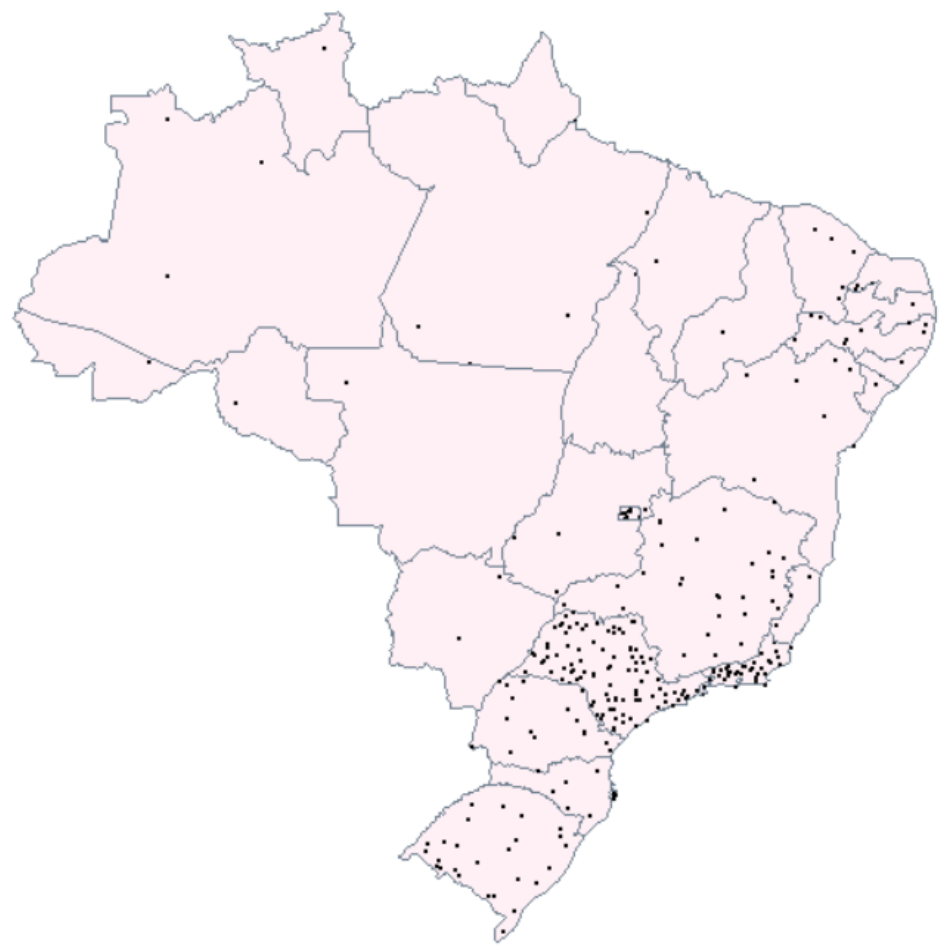

Fonte: Dados da pesquisa.

Nota: unidades federativas contabilizadas uma única vez em cada artigo.

Figura 3 - Distribuição da pesquisa em Ciências Biomédicas no território brasileiro entre 2006 e 2015,1 ponto $=501,32$ artigos, peso relativo.

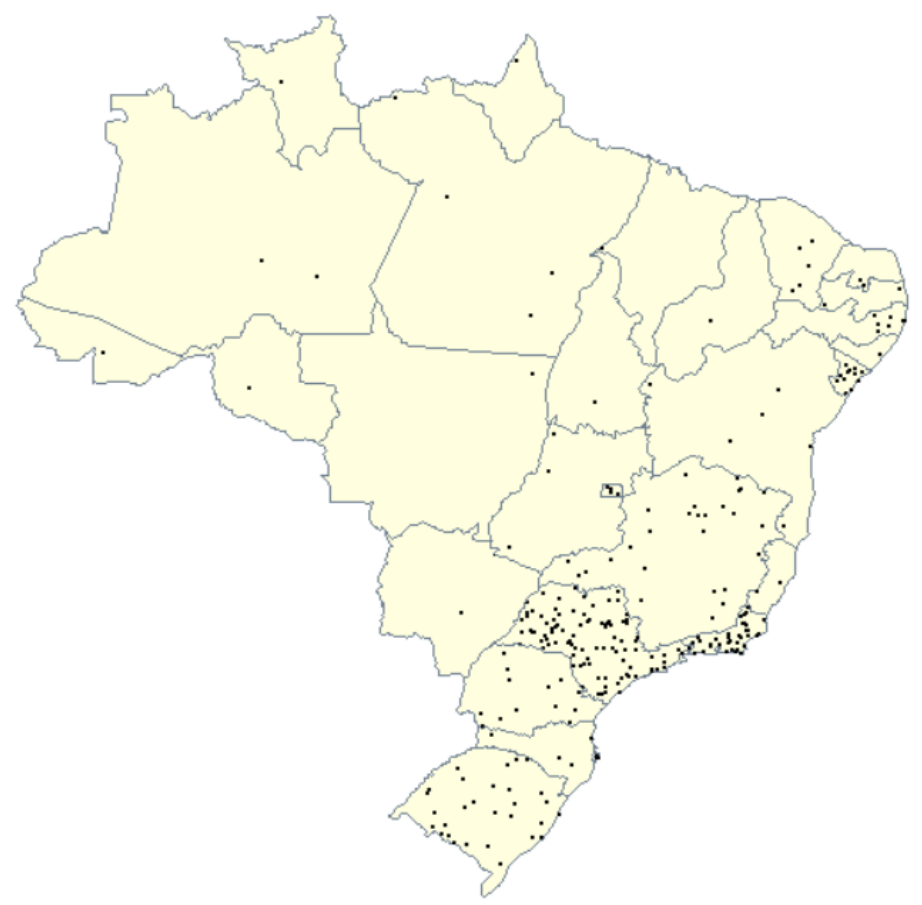

Fonte: Dados da pesquisa.

Nota: diferentemente da Tabela 1 e da Figura 2, neste mapa foi levado em consideração o número 
de pesquisadores que assinaram cada artigo (peso relativo), a fim de se ponderar sobre a distribuição da atividade científica no território nacional. Isso significa que cada estado pode contar mais de uma vez por artigo dependendo do número de autores, por isso cada ponto representa um número muito maior de artigos do que no mapa da Figura 2.

A Figura 2 apresenta um mapa da distribuição da produção científica brasileira em Ciências Biomédicas, no qual cada ponto vale 256,04 artigos. Nesse mapa cada estado foi pontuado uma única vez, mesmo que o artigo indicasse vários autores provenientes do mesmo estado. Já a Figura 3 ponderou o número de autores de cada estado, e nesse caso, os estados foram contados tantas vezes quanto apareceram na filiação dos autores dos artigos. Cada ponto representa 501,32 artigos. Tal resultado demonstra o grande predomínio de pesquisadores do estado de São Paulo, além de outros estados das regiões Sudeste e Sul.

A colaboração na pesquisa, facilitada pela proximidade geográfica, é um fator que pode contribuir para a concentração da produtividade em determinadas regiões. A análise de colaboração por meio da coautoria expressa nos artigos indica que esse fator é preponderante na produção científica em Ciências Biomédicas no território brasileiro, visto que os clusters são formados por estados da mesma região ou próximos geograficamente, conforme demonstrado na Figura 4. 


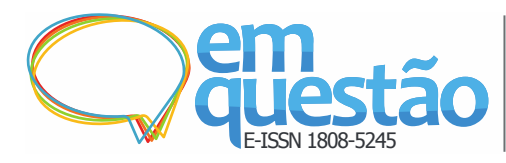

Distribuição geográfica da produção e colaboração científica brasileira nas Ciências Biomédicas

Natascha Helena Franz Hoppen, Dirce Maria Santin, Mauricio de

Vargas Corrêa, Samile Andréa de Souza Vanz

Figura 4 - Colaboração nas Ciências Biomédicas entre as unidades federativas brasileiras, 20062015.

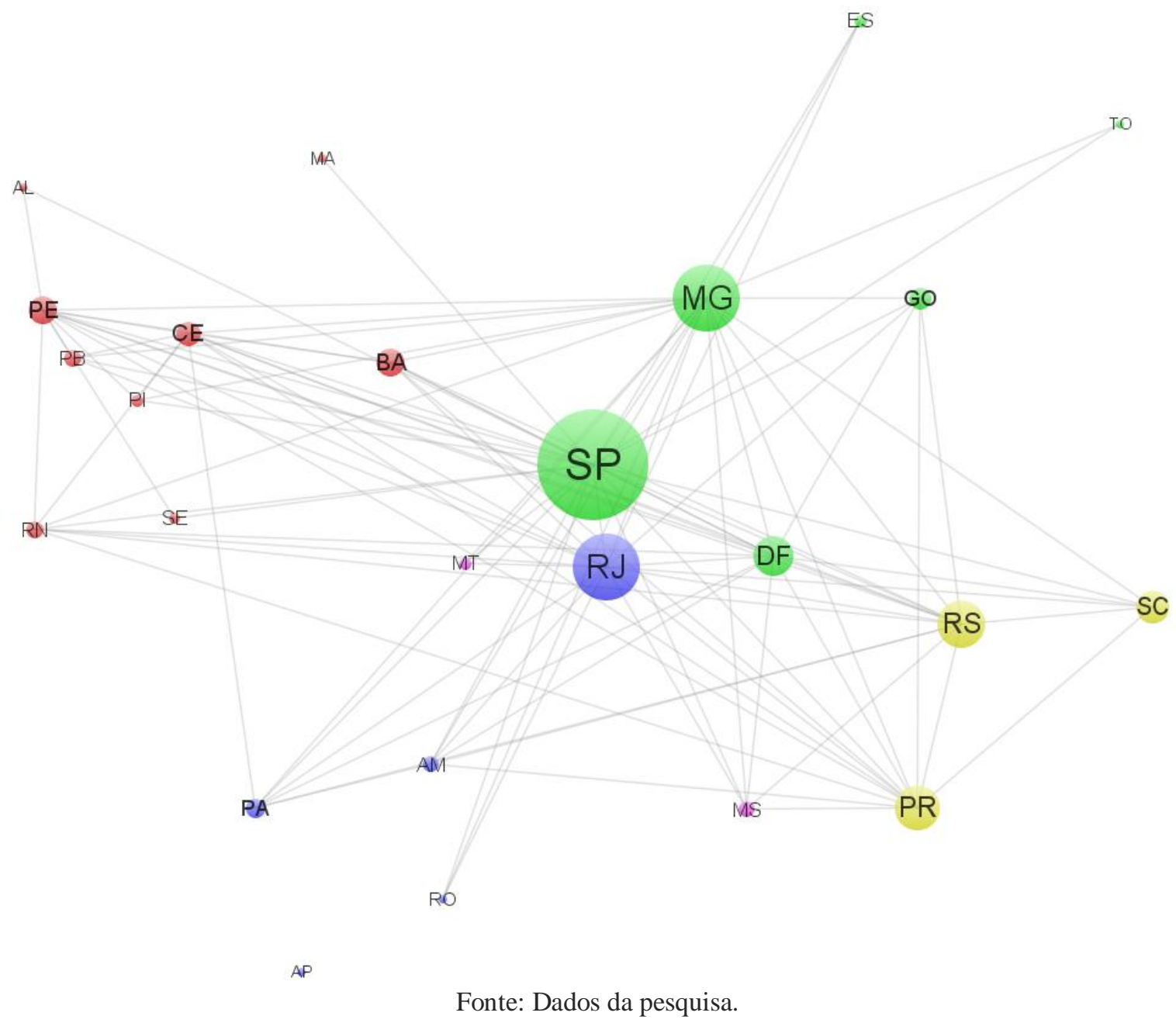

São Paulo aparece no centro do mapa com ligações para todos os outros clusters, demonstrando que colabora com diversos estados do país. Quatro clusters de colaboração são identificados na Figura 4. O amarelo é composto pelos três estados do sul do país (Rio Grande do Sul, Santa Catarina e Paraná). O verde é composto por UFs das regiões Sudeste (São Paulo, Minas Gerais e Espírito Santo) e Centro-Oeste (Distrito Federal, Goiânia e Tocantins). Apesar de serem considerados de regiões distintas, esses estados se encontram próximos geograficamente. O cluster vermelho é composto por Pernambuco, Alagoas, Maranhão, Paraíba, Piauí, Rio Grande do Norte, Sergipe, Ceará e Bahia, todos estados do nordeste brasileiro. O cluster rosa é o menor de todos, composto pelos estados do Mato Grosso e do Mato Grosso do Sul, que fazem fronteira entre si e se diferenciam pela proximidade com clusters de outras regiões: Mato Grosso do Sul está mais próximo ao cluster dos estados do sul (amarelo) e Mato Grosso, do 
cluster que contém estados do centro-oeste (verde).

Por meio da análise do mapa pode-se inferir que Pernambuco desempenha importante papel na região Nordeste, visto ser um estado bastante produtivo, que colabora com todos os demais próximos, além de ser aparentemente autônomo em relação aos estados com maior atividade científica. Situação similar se observa no Rio de Janeiro, que aparenta ter uma posição peculiar no mapa de colaboração: encontra-se próximo a São Paulo (sendo os dois estados mais produtivos), mas pertence ao grupo em que estados menos produtivos colaboram (Amazonas, Pará, Rondônia, Amapá e Acre, todos estados do norte do país). Pode-se inferir que o Rio de Janeiro tem uma função peculiar nessa rede de colaboração, visto que é um estado que se destaca na produtividade científica das Ciências Biomédicas brasileiras.

\section{Conclusões}

Cada país tem sua própria história da ciência e inovação, inspiradas não só pela curiosidade dos pesquisadores, mas também pela necessidade social. Conhecer a perspectiva histórica e avaliar os resultados atuais da ciência são processos fundamentais para garantir subsídios às políticas científicas e melhorar a capacidade e a estrutura científica de um país.

A produção científica brasileira em Ciências Biomédicas apresenta um crescimento linear na última década, contudo há heterogeneidade na distribuição e na colaboração científica entre os estados. São Paulo desponta como o estado mais produtivo e colaborativo: está presente em quase 50\% dos artigos publicados e colabora com todos os clusters, apesar de estar mais próximo geograficamente a Minas Gerais e estados da região Centro-Oeste. Tal resultado pode decorrer do histórico de criação das instituições de pesquisa, além do financiamento advindo da Fundação de Amparo à Pesquisa do Estado de São Paulo (FAPESP). Os estados do nordeste, pioneiros na pesquisa em saúde no país, têm desenvolvimento mais lento se comparados aos estados do sudeste e do sul. O histórico demonstra que a liderança de São Paulo, por exemplo, se deu, entre outros fatores, devido a um surto de doença contagiosa na região no início do 
século XX. Atualmente a situação do Zika Vírus no Brasil tem seu foco nos estados do norte e nordeste do país e pode servir como impulso às pesquisas da área na região.

A proximidade geográfica é um fator importante na colaboração e mesmo na produtividade, tendo em vista que estados mais produtivos estão próximos de outros também produtivos. Pernambuco se destaca pela sua produtividade na região Nordeste, apesar de se situar em posição inferior aos estados do sudeste e do sul, que lideram o ranking; e Rio de Janeiro colabora especialmente com estados do norte do país, que são os menos produtivos (presentes no mesmo cluster).

É um fato notável que a disparidade de produção científica entre regiões ocorre em todos os países. Alguns autores têm o entendimento de que esse é um fato natural e até necessário, visto que é preferível direcionar esforços e recursos aos centros já desenvolvidos a fim de torná-los cada vez melhores e mais produtivos, em vez de alocar recursos para locais onde a contrapartida em termos de pesquisa e seu desenvolvimento é baixa ou inexistente. Todavia, é um fato também que as maiores diferenças de desenvolvimento e produtividade científicas entre regiões ocorre em países em desenvolvimento. Por si só essa constatação já demonstra que as diferenças são comuns, mas o problema pode estar na intensidade das diferenças. Além disso, é necessária uma atenção especial para as áreas científicas ligadas à saúde, já que, embora possam ter como foco a pesquisa básica (de interesse global), também têm como propósito a investigação de questões de saúde locais, o que significa que a inexistência ou baixa ocorrência de pesquisa em determinadas regiões pode ser sinônimo de não investigação de questões da saúde local. Num país tão diverso e vasto geograficamente como o Brasil, o não desenvolvimento da pesquisa em Ciências Biomédicas em alguns estados e regiões, ou sua incipiência de longa data, não são positivos e/ou desejáveis.

Os dados apresentados neste estudo se referem ao número de artigos publicados e à colaboração expressa nas publicações. Acredita-se que resultados sobre a produção e a colaboração científica, e sua relação geográfica, podem apoiar decisões acerca das políticas brasileiras de ciência, tecnologia e inovação 
voltadas às Ciências Biomédicas.

\section{Referências}

ALMEIDA, Elenara Chaves Edler de; GUIMARÃES, Jorge Almeida. Brazil's growing production of scientific articles - how are we doing with review articles and other qualitative indicators? Scientometrics, Dordrecht, v. 97, n. 2, p. 287-315, 2013.

BENCHIMOL, Jaime Larry. Febre amarela e a instituição da microbiologia no Brasil. In: HOCHMAN, Gilberto; ARMUS, Diego (Org.). Cuidar, controlar, curar: ensaios históricos sobre saúde e doença na América Latina e Caribe. Rio de Janeiro: Fiocruz, 2004. p. 57-97. (Coleção História e Saúde).

BRASIL. Lei $n^{\circ}$ 5.540, de 28 de novembro de 1968. Fixa normas de organização e funcionamento do ensino superior e sua articulação com a escola média, e dá outras providências. Diário Oficial [da] República Federativa do Brasil, Brasília, DF, 29 nov. 1968. Seção 1, p. 10369.

CAMARGO, Erney Plessmann; SANT'ANNA, Oswaldo Augusto. Institutos de pesquisa em saúde. Ciência \& Saúde Coletiva, Rio de Janeiro, v. 9, n. 2, p. 295-302, abr./jun. 2004.

CASTRO, Cláudio Moura. Ciência e universidade. Rio de Janeiro: Jorge Zahar, 1986.

ESCOLA de Cirurgia da Bahia. In: DICIONÁRIO histórico-biográfico das ciências da saúde no Brasil (1832-1930). [Rio de Janeiro: FIOCRUZ, 2015.] Disponível em:

<http://www.dichistoriasaude.coc.fiocruz.br/iah/pt/pdf/escirba.pdf >. Acesso em: 27 ago. 2016.

FUNDAÇÃO DE AMPARO À PESQUISA DO ESTADO DE SÃO PAULO. Indicadores de ciência e tecnologia e inovação em São Paulo 2010. São Paulo: FAPESP, 2011.

GLÄNZEL, Wolfgang; LETA, Jacqueline; THIJS, Bart. Science in Brazil. Part 1: a macro-level comparative study. Scientometrics, Dordrecht, v. 67, n. 1, p. 67-86, 2006.

GLÄNZEL, Wolfgang; SCHUBERT, András. A new classification scheme of science fields and subfields designed for bibliometric evaluation purposes.

Scientometrics, Dordrecht, v. 56, n. 3, p. 357-367, 2003.

HOPPEN, Natascha Helena Franz; VANZ, Samile Andréa de Souza.

Neurosciences in Brazil: a bibliometric study of main characteristics, collaboration and citations. Scientometrics, Dordrecht, v. 109, n. 1, p. 121-141, 2016. 
LABORATÓRIO de Bacteriologia do Estado de São Paulo. In: DICIONÁRIO histórico-biográfico das ciências da saúde no Brasil (1832-1930). [Rio de Janeiro: FIOCRUZ, 2015.] Disponível em:

〈http://www.dichistoriasaude.coc.fiocruz.br/iah/pt/pdf/labbacesp.pdf $>$. Acesso em: 11 set. 2016.

LETA, Jacqueline; GLÄNZEL, Wolfgang; THIJS, Bart. Science in Brazil. Part 2: sectorial and institutional research profiles. Scientometrics, Dordrecht, v. 67, n. 1, p. 87-105, 2006.

LETA, Jacqueline; THIJS, Bart; GLÄNZEL, Wolfgang. A macro-level study of science in Brazil: seven years later. Encontros Bibli, Florianópolis, v. 18, n. 36, p. 51-66, 2013.

LETA, Jacqueline. Growth of Brazilian science: a real internalization or a matter of databases' coverage? In: INTERNATIONAL CONFERENCE OF THE INTERNATIONAL SOCIETY FOR SCIENTOMETRICS AND INFORMETRICS, 13., 2011, Durban. Proceedings... Durban: ISSI, 2011. Vol. 1, p. 392-397.

MEIS, Leopoldo de; LETA, Jacqueline. O perfil da ciência brasileira. Rio de Janeiro: UFRJ, 1996.

MOTOYAMA, Shozo. Prelúdio para uma história: ciência e tecnologia no Brasil. São Paulo: USP, 2004.

ROYAL SOCIETY. Knowledge, networks and nations: global scientific collaboration in the $21^{\text {st }}$ century. London: Elsevier, 2011.

ROSSI, Marina. Cortes de vagas, de luz e bancas por Skype: o ajuste bate à porta das universidades: após dois anos de contingenciamento, Ministério da Educação planeja corte de até $45 \%$ nos investimentos das universidades federais. El País, [S.1.], 6 set. 2016. Educação. Disponível em:

<http://brasil.elpais.com/brasil/2016/08/23/politica/1471981749 096592.html>.

Acesso em: 6 set. 2016.

SANTIN, Dirce Maria; VANZ, Samile Andréa de Souza; STUMPF, Ida Regina Chittó. Internacionalização da produção científica em ciências biológicas da UFRGS: 2000-2011. Transinformação, Campinas, v. 27, n. 3, p. 209-218, set./dez. 2015.

SCHWARTZMAN, Simon. Um espaço para a ciência: a formação da comunidade científica no Brasil. Brasília: Ministério de Ciência e Tecnologia, 2015 .

SIDONE, Otávio José Guerci; HADDAD, Eduardo Amaral; MENA-CHALCO, Jesús Pascual. A ciência nas regiões brasileiras: evolução da produção e das redes de colaboração científica. Transinformação, Campinas, v. 28, n. 1, p. 15-32, jan./abr. 2016. 
SIDONE, Otávio José Guerci; HADDAD, Eduardo Amaral; MENA-CHALCO, Jesús Pascual. Scholarly publication and collaboration in Brazil: the role of geography. Journal of the Association for Information Science and

Technology, Hoboken. v. 68, n. 1, p. 243-258, 2017.

VALLE, José Ribeiro do. A farmacologia no Brasil. In: FERRI, Mário Guimarães; MOTOYAMA, Shozo. História das ciências no Brasil. São Paulo: EdUSP, 1979. p. 175-189.

VANZ, Samile Andréa de Souza; STUMPF, Ida Regina Chittó. Scientific output indicators and scientific collaboration network mapping in Brazil. Collnet, New Delhi, v. 6, p. 1-20, 2012.

WORLD HEALTH ORGANIZATION. The world health report 2001: mental health, new understanding, new hope. Geneva: WHO, 2001.

\title{
Geographical distribution of Brazilian scientific production and collaboration in Biomedical Sciences
}

\begin{abstract}
The Biomedical Sciences constitute an important field of research in Brazil, both by the study of typical local diseases and by focusing on subjects of universal interest. This study initially makes a survey of the institutionalization of Biomedical Sciences in Brazil and subsequently analyzes the geographical distribution of production and scientific collaboration in these areas in the country in order to understand the current settings of the field and the concentration and dispersion of research in the national territory. This is a bibliometric study based on articles published in the last decade (2006-2015) by Brazilian researchers in journals indexed in the Web of Science. The results show the concentration of production in a few states, especially São Paulo, present in almost $50 \%$ of the articles and the most collaborative among the federal units from other regions of the country. Another highlight is the state of Rio de Janeiro, the second most productive and responsible, along with São Paulo, for the five journals that most published Biomedical Sciences articles in the period under study. Minas Gerais, Rio Grande do Sul, Paraná and Santa Catarina are the next states in terms of productivity. Federal units of the same region or geographically close form collaboration clusters. Pernambuco and Espírito Santo are also states highlighted for their modes of production and collaborative role in their clusters. The country's northern states are the least productive followed by those of the Northeast, which indicates the need for more public policies for scientific development of these regions. The conclusion says that geographical proximity is an important factor in cooperation and even productivity considering that federal units that are more productive are close to each other and show huge collaboration between them.
\end{abstract}


Keywords: Scientometrics. Bibliometrics. Biomedical Sciences. Brazil. Scientific production. Scientific collaboration. Collaboration networks. Geographical analysis.

${ }^{1}$ EDLER, Flavio Coelho. A constituição da medicina tropical no Brasil oitocentista: da climatologia à parasitologia médica. 1999. Tese (Doutorado) - Instituto de Medicina Social, Universidade do Estado do Rio de Janeiro, Rio de Janeiro, 1999.

Recebido em: 19/09/2016

Aceito em: 21/10/2016 